\title{
Inter-Organizational Governance and Trilateral Trust Building: A Case Study of Crowdsourcing-based Open Innovation in China
}

\begin{abstract}
China has stepped into the Internet era with the emergence of a large number of e-

commerce players. However, Internet-based crowdsourcing of R\&D projects, a primary form of open innovation, is still lacking. In a case study of a Chinese crowdsourcing intermediary (CI), the authors explore the impact of inter-organizational governance on trilateral trust building. They show that formal control and relational governance mechanisms are essential for swiftand knowledge-based trust in R\&D crowdsourcing. The case also indicates that Chinese businesses continue to use guanxi (informal personal connections) as a relational and contingent mechanism to maintain affect-based trust, but guanxi is shown to inhibit the growth of Internetbased crowdsourcing for open innovation in China.
\end{abstract}

Key Words: Chinese context, crowdsourcing, open innovation, R\&D, trust 


\section{Introduction}

Scientists and organizations are increasingly and broadly collaborating in engineering, computer sciences, chemistry, life sciences, and physical sciences research and development $(\mathrm{R} \& \mathrm{D})$ projects through crowdsourcing intermediary $(\mathrm{CI})$ platforms such as innocentive.com, innovationexchange.com, and yourcencore.com (Chesbrough, 2006). Companies are now widely accepting $R \& D$ crowdsourcing as a primary means for reducing the costs of $R \& D$ for innovation needs (West \& Bogers, 2014). As China steps into the Internet era, many ecommerce players, Internet users, and websites have emerged to perform tasks such as logo and website designs and translation services. Although China's rapid economic growth has increased the demand for R\&D, Internet-based open innovation platforms present a dual challenge (Gassmann \& Han, 2004). Most small and medium enterprises (SMEs) lack internal R\&D workforces, but China has a large pool of talent able to conduct essential R\&D projects. However, China's companies and research institutions resist placing such high-value R\&D projects on crowdsourcing websites, and few researchers have systematically addressed how the resistance affects the growth of $\mathrm{R} \& \mathrm{D}$ crowdsourcing for innovation in the Chinese context.

Crowdsourcing is an effective approach to innovation, but to avoid exchange hazards, build trust in online environments, and form customer-client relationships, crowdsourcing sites need formal controls such as written contracts, feedback, escrow services, and credit card guarantees (Ulset, 1996; Willamson, 1985). They also need relational governance emphasizing mutual trust, relational capital, communication, and collaboration (Dyer \& Singh, 1998; Lee \& Cavusgil, 2006). Inter-organizational trust is essential for business transactions and building successful long-term relationships and alliances among companies (Zaheer, McEvily, \& Perrone, 1998; 
Zaheer \& Venkatraman, 1995). The extant literature mainly focuses on trust-building of vendorclient or alliance bilateral relationships, but few studies examine trust building of trilateral relationships comprising intermediaries that facilitate activities between two companies (Gefen \& Straub, 2004; Pavlou \& Gefen, 2004; Stewart, 2003). Because Internet intermediaries replace traditional agents in connecting geographically separated vendors and clients, we lack sufficient knowledge about trust development in the virtual world among clients, online intermediaries, and vendors in the context of crowdsourcing-based open innovation.

Drawing from the literature on inter-organizational governance and trust development, we address a research question: how can inter-organizational governance mechanisms be adapted to enhance trilateral trust building in crowdsourcing-based innovation in China? By focusing on the Chinese context and by using a case study, we provide additional insights into how Chinese firms utilize inter-organizational governance mechanisms for open innovation. We find that Chinese $\mathrm{CI}$ differs from western practices where $\mathrm{CI}$ is an open platform for inter-organizational exchanges to accomplish R\&D crowdsourcing tasks. Instead, Chinese CIs more intensively govern crowdsourcing processes, trilateral interactions, and trust-building between users, but lack proper formal control and relational mechanisms to manage swift- and knowledge-based trust. More importantly, we find that Chinese CIs utilize guanxi, or informal personal connections, to maintain affect-based trust. Based on the case findings, we propose that guanxibased relational governance challenges open innovation and prevents organizations from utilizing online crowdsourcing for $R \& D$ projects.

This study makes several important theoretical contributions to the open innovation literature. Foremost are theoretical contributions that incorporate the literature of interorganizational governance and trust development. Our study underscores that CIs must have 
appropriate governance mechanisms to develop swift- and knowledge-based trust among crowdsourcers, crowdsourcees, and CIs. We also contribute to the literature of open innovation by identifying effective governance mechanisms specific to the Chinese context (Byrum \& Bingham, 2016). Second, extending the inter-organizational governance literature and ecommerce trust concept (Ba \& Pavlou, 2002; Benbasat, Gefen, \& Pavlou, 2008) to the crowdsourcing context, we contribute to understandings of trust building in trilateral business relationships (Svensson, 2004) and show that swift- and knowledge-based trust is essential if crowdsourcing is to grow. Third, we offer additional understanding of guanxi's (Chen et al., 2013) double-edged functions in governing relations but preventing the growth of crowdsourcing-based open innovation in China.

The paper is organized as follows: First, we discuss the related literature highlighting the roles of crowdsourcing-based open innovation. Then we discuss inter-organizational governance and trust development in the crowd-sourcing environment. We introduce our research context and methods, followed by our main findings and discussion.

\section{Crowdsourcing-Based Open Innovation}

Open innovation is defined as an approach that firms use to acquire external knowledge across industries to complement their internal knowledge base, to advance their technology, and to acquire competitive advantage (Chesbrough, 2003, 2006). Firms often use internal employees or the community for open innovation, but most frequently rely on online crowdsourcing for sundry purposes (Cabiddu, Castriotta, Di Guardo, \& Floreddu, 2013; Sieg, Wallin, \& Von 
Krogh, 2010), from simple letter writing or graphic design projects to complex R\&D innovation (Andriole, 2010; Erickson, 2012).

Online crowdsourcing website stakeholders include crowdsourcers, crowdsourcees, and crowdsourcing intermediaries (CIs) (Brabham, 2008; Cabiddu et al., 2013; Majchrzak \& Malhotra, 2013). Crowdsourcers initiate the crowdsourcing process by submitting task requests and specifying the acceptance criteria. Crowdsourcees are registered members who are paid by the clients to undertake and execute tasks. $C I s$ are the online brokerage companies acting as intermediaries or virtual knowledge brokers (Frey, Lüthje, \& Haag, 2011; Howells, 2006; Katzy, Turgut, Sailer, \& Klaus, 2013; Verona, Prandelli, \& Sawhney, 2006), ensuring that crowdsourcees successfully complete projects and that crowdsourcers pay for the services (Zogaj, Bretschneider, \& Leimeister, 2014).

Because CIs are increasingly important for driving open innovation, management scholars have turned attention to research on crowdsourcing (Chesbrough, 2006) to learn motivations for participating (Frey et al., 2011), the design of open innovation contests (Cabiddu et al., 2013; Terwiesch \& Xu, 2008), managerial challenges and remedies for solving R\&D problems through innovation intermediaries (Sieg et al., 2010), product solution capabilities and added value for product development processes (Tran, Hsuan, \& Mahnke, 2011), and ways to attract participants that can substantially contribute to innovation challenges (Frey et al., 2011). Nevertheless, research needs more emphasis on governance, technology, and crowdsourcing outcomes (Pedersen et al., 2013). In summary, the literature has recognized that CIs are essential 
for driving open innovation, but we need further understandings of how the Internet environment can successfully manage $R \& D$ projects.

\section{Inter-Organizational Governance Mechanisms and Trust building in Crowdsourcing}

Studies of inter-organizational sourcing relationships have focused on two governance mechanisms: formal controls and relational governance. Formal controls are "the written contracts and institutional mechanisms designed to guide behaviors toward desired objectives, whereas relational governance is unwritten, work-based mechanisms designed to influence interorganizational behavior" (Goo, Kishore, Rao, \& Nam, 2009, P. 120). Contracts are useful for preventing exchange hazards (Ulset, 1996; Willamson, 1985). In addition, CIs, as transaction intermediaries, can use "third-party institutional structures that provide a rational basis for interaction among marketplace participants" (Pavlou \& Gefen, 2004, p.41), such as feedback, escrow services, and credit card guarantees for gaining trust.

Mutual trust, relational capital (Dyer \& Singh, 1998; Lee \& Cavusgil, 2006), and social actions such as open communication and cooperation (Goo et al., 2009; Lacity, Khan, \& Willcocks, 2009) are essential for forming buyer-supplier relationships. Relational governance improves the performance of inter-organizational exchanges in general (McEvily, Perrone, \& Zaheer, 2003) and IT outsourcing in particular (Sabherwal, 1999). Even the most fundamental discrete exchanges include some relational elements (Macneil, 1980).

Mutual trust is essential for alliance success and performance (Zaheer et al., 1998; Zaheer \& Venkatraman, 1995). To maintain long-term and healthy relationships between organizations, vulnerability must be reduced (Bachmann \& Inkpen, 2011; Doney \& Cannon, 1997; Gambetta, 
1988; Katsikeas, Skarmeas, \& Bello, 2009; Kee \& Knox, 1970). Trust is even more important for enabling online transactions among geographically dispersed users who lack prior history in information and communication technologies (ICT).

Before interactions occur, CIs can build swift trust based on third-party guarantees and recommendations (Shapiro, 1987; Zucker, 1986). Institutional warrants ease the development of swift trust (Kramer, 1999). In the crowdsourcing marketplace, third-party recommendations act as institution-based swift trust that users can generalize and transfer to related entities (Hamilton \& Sherman, 1996; Stewart, 2003). Swift trust then transfers from CI to the crowdsourcers and crowdsourcees who lack previous transaction history. After initial contacts, however, knowledge-based trust depends on personal knowledge about past behaviours (Robert, Denis, \& Hung, 2009). Online members may need a longer time to assess whether they can trust other members.

In traditional trading contexts, trade intermediaries go between sourcers (buyers) and sourcees (suppliers). Therefore, intermediaries must develop mutual trust with sourcers and sourcees; sourcers and sourcees share no direct contact and trust building with each other. However, crowdsourcing trust elements require trilateral trust building among CIs, sourcers, and sourcees. Trilateral trust is a dynamic construct: outcomes depend on mutual perceptions in the trilateral business network (Svensson, 2004). Therefore, as Figure 1 shows, the triadic nature of the relationship adds complexity to inter-organizational exchanges. It entails six types of interorganizational trust-building: (1) crowdsourcer trust in the $\mathrm{CI}$, (2) crowdsourcer trust in the crowdsourcees, (3) crowdsourcee trust in the CI, (4) crowdsourcee trust in the crowdsourcers, (5) 
CI trust in the crowdsourcers, and (6) CI trust in the crowdsourcees. Crowdsourcers, crowdsourcees, and CIs can be trustors or trustees.

\section{Insert Figure 1 About Here}

First, both crowdsourcers and crowdsourcees must trust the CI. CIs must provide reliable, secure, and fair online platforms with open rules and procedures. They must use accredited sourcers/sourcees who register online and encourage benevolent transaction norms. If sourcers and sourcees lack initial trust, they will not sign up with the CI or continue operating in the crowdsourcing environment.

Second, as intermediaries, CIs must trust sourcees for having the ability, skills, and competency they claimed to be certified, and must trust that sourcers who initiate the sourcing process will honour their promises to pay the sourcees once the tasks are completed satisfactorily. Thus all three entities must trust each other to complete the dynamic transaction system. Any missing links will cause the crowdsourcing project to fail.

\section{Guanxi and Affect-Based Trust Building}

Swift trust is institution-based (Kramer, 1999); knowledge-based trust is cognition-based (Chua, Morris, \& Ingram, 2009). Affect-based trust is unique in the Chinese context (Chen, Chen, \& Huang, 2013; Park \& Luo, 2001). China is generally less trusting than comparable countries (Bjørnskov, 2007). From individualist and collectivist country perspectives, Chinese people tend to have lower-levels of trust than do citizens of the United States and Germany (Huff \& Kelley, 2003). Chinese business people are less able to overcome the sense of distrust that naturally 
exists between potential partners, especially in the initial stages of business relationships (Davison \& Ou, 2008). Guanxi, an embedded and sophisticated concept in the Chinese trust context, plays an essential role in trust building. Guanxi indicates pre-existing personal connections and informal social networks (Hennart, 2015) with trust, bonding, reciprocity, and empathy dimensions (Park \& Luo, 2001; Wong, 2007), based at interpersonal/individual levels rather than being in "the system" (Martinsons, 2008). In general, guanxi is a major factor for successfully conducting business and building partnerships in China (Millington, Eberhardt, \& Wilkinson, 2005; Park \& Luo, 2001; Wong, 2007). Guanxi networks are essential for developing successful inter-company relationships (Hutchings \& Murray, 2002). Guanxi causes affect- and cognition-based trust to be more intertwined for Chinese managers in business transactions (Chua et al., 2009).

In the context of online intermediaries in China, B2B platforms such as alibaba.com explicitly represent trustworthy knowledge, enhance supplier selection, and diminish the salience of guanxi networks (Davison \& Ou, 2008). However, high-stake R\&D crowdsourcing projects are more complex than B2B platforms and require higher trust levels (Das \& Teng, 1998; Economist Intelligence Unit, 2008). It is unclear whether Chinese companies can transact with distant parties and develop new partnerships without utilizing guanxi.

\section{Methods}

\section{Research design}

Recognizing the lack of prior research, we chose case study (Miles \& Huberman, 1994) as our method for observing the uptake and development of R\&D crowdsourcing in China. The 
case study approach is particularly useful for observing, explaining, and exploring new phenomena within their real-life setting, especially for answering why and how questions (Verner \& Abdullah, 2012) and for investigating unclear boundaries between contemporary phenomena and their context (Myers, 2013; Yin, 2003).

The unit of analysis is an R\&D crowdsourcing project between the QC Corporation as crowdsourcer, cs.com as the CI intermediary, and Jack and Rachel, two actual crowdsourcees. The cs.com company was expanding its CI business into R\&D crowdsourcing, and asked the authors to be outside observers for identifying the opportunity and challenges of R\&D crowdsourcing activities. In response, the authors gathered feedback regarding the launch, implementation, and transaction of the project, in accordance with previous studies in which the authors had active and full access to the research site and with data sources, and were able to engage in extensive observation despite having minimal research resources (Heiskanen, Newman, \& Eklin, 2008).

\section{Data collection}

The data were collected after the event and activities had already occurred and the outcomes were known. Retrospective researchers can observe final process outcomes. Consequently, retrospective designs are popular for learning about the past in organizational and strategic management research (Golden, 1997; Miller \& Glick, 1997) and organization theory research (Bourgeois \& Eisenhardt, 1988; Feeser \& Willard, 1989; Huber \& Power, 1985).

The primary data came from eleven written questionnaires with open questions. (See the appendix.) Questionnaires were mailed to participants because geographic and time-zone 
differences prevented face-to-face interviews. Participants included the general manager of cs.com, responsible for the general operation and management of the CI; the chief technical officer who manages the IT-infrastructure and technical background of the CI; one crowdsourcer; and two crowdsourcees involved in the crowdsourcing project. Cs.com initially invited six other companies to use crowdsourcing, and they also answered questionnaires after we reached them through the personal networks of the manager of cs.com. The six companies were from knowledge-intensive industries potentially needing R\&D outsourcing such as IT, telecommunications, and aerospace. Approximately a month passed before all participants returned the questionnaires. The questionnaires were originally conducted in Chinese, but we then translated the key points into English. The questions included aspects of overall experiences and concerns about participating in $\mathrm{R} \& \mathrm{D}$ crowdsourcing projects. The participants were also asked whether the Chinese context affected their trust. They also gave suggestions for growing $R \& D$ crowdsourcing in China.

For triangulation purposes, we collected additional documents (Myers, 2013) such as archival project documents, memos, reports, intermediary webpages, and trial working documents stored on the website. We also conducted real-life observations throughout the project's lifecycle to observe how the events evolved from initiation to completion.

\section{Data analysis}

We examined the data using thematic analysis, widely used in qualitative research (Saldaña, 2012), to create meaningful patterns. Researchers study the data, generate initial codes, search for themes; review, define, and name the themes; and produce a final report. 
In addition to thematic analysis, we adopted "reflection in action" (Schön, 1983) in which hypotheses are generated based on data acquired during case development (Heiskanen et al., 2008). The idea was later developed to mean that researchers report their direct experience in a way that makes sense to both academic and practical audiences (Heiskanen, 1995; Heiskanen \& Newman, 1997). The goals are to reflect on how a problem is solved, to observe the event procedures and sequences, and to rethink the presuppositions.

\section{The case of $R \& D$ crowdsourcing at cs.com}

The high-tech QC Corporation (QC) is located in Henan Province, China. Founded in 2006 with the support of the Development and Reform Commission of Henan Province, QC's primary business is electric automobiles, energy conservation, and alternative energy products. As a pioneer in promoting and producing electric automobiles in China, QC saw a need for a comprehensive analytical report examining the whole industry.

Cs.com, a crowdsourcing intermediary startup based in Shanghai, recently launched its CI website, aiming to position itself as an innovation platform for finding external talents for highly complex and challenging projects. In December 2010, QC licensed cs.com to crowdsource the QC Corporation Electric Automobile Production Feasibility Analysis Report, for $¥ 150,000$ RMB (approximately $\$ 24,000$ USD). To advertise the project, the staff of cs.com extensively publicized it and the CI platform through posts in public forums, university forums, university teach-ins, and emails from December 2010 through January 2011. About 20 crowdsourcees submitted proposals to cs.com. Rachel, a graduate student from a prestigious university in China, 
with little working experience, won the bid and contracted with cs.com to finish the report between February 1, 2011 and May 31, 2011.

Around April 15, 2011, the cs.com staff reminded Rachel of the approaching deadline and prompted her to hand in her half-finished proposal. Surprisingly, she had failed to make substantial progress because she had received other unexpected work. On May 1, 2011, she hastily submitted an unsatisfactory draft report. According to her contract, she should have received no payment, but cs.com recognized the work she had done by giving her $30 \%$ of the total payment.

The cs.com staff was highly frustrated. The manager then used his personal guanxi to find Jack, an expert with more than 20 years of experience working at a research institute, and hired him to complete the work by the end of June. The manager of cs.com negotiated with QC to extend the project deadline so that cs.com received no fine. Jack submitted the report at the end of June. Luckily, QC was satisfied with the final report and did not reduce the payment for the one-month delay. QC executed the payment on July 15, 2011. Jack got 70\%, but cs.com made nothing for facilitating the project.

\section{Results}

Our theoretical background and the observation made it apparent that three main dimensions of trust were involved in the case of R\&D crowdsourcing: swift trust, knowledgebased trust, and affect-based trust. Our respondents provided vivid accounts of difficulties in implementing R\&D crowdsourcing in the Chinese context. Figure 2 shows a summary of the results from the perspectives of inter-organizational governance and trust development. 
Insert Figure 2 About Here

\section{Formal control mechanisms and swift trust}

In the crowdsourcing context, swift trust is established before anyone has knowledge about members' prior behaviour (Robert et al., 2009). As the starting point for sourcers and sourcees, building swift trust and eliminating scepticism about opportunism is essential. Control mechanisms can reduce the threat of opportunism and governance costs (Hödl \& Puck, 2014), so CIs should establish formal control mechanisms to develop swift trust in the Internet environment. Our case study shows that the CI failed to provide the necessary formal control mechanisms to promote swift trust.

The crowdsourcing marketplace vitally needs a large talent pool of people with knowledge, backgrounds, and skills. QC indicated that one concern they had about using the CI was whether it would have access to adequate talent that could complete the task successfully. To build the sourcers' swift trust regarding sourcees, CIs must form highly recommended and large talent pools based on experience and qualifications. The general manager of cs.com commented:

Now it's really the key to establish a large talent pool that can meet all kinds of needs.

The company might not be looking for the top one among the talent pool, but they surely would look for the most appropriate one to do their work.

Thus crowdsourcers must have access to a large talent pool and must provide the most appropriate workers. A recommendation system is the most effective institutional governance to 
match appropriate talents to tasks and to help crowdsourcers develop swift trust towards CIs.

QC distrusted working with an unfamiliar individual, particularly for a high value R\&D project:

Usually, we prefer to outsource a task to people that we know or we have cooperated with before. It would be hard for us to accept the new model [crowdsourcing platform] first, while at the same time outsourcing R\&D to someone we don't know. We need to escrow a big amount of money on the website and wait for a result that we are uncertain of.

Although I know the manager well, I still have doubts about whether the firm can solve my problem.

Because the sourcers and sourcees lack prior knowledge of each other, speculation and mistrust inhibit the initial contact. Rachel and Jack expressed the same concerns as sourcees. They mentioned the uncertainty factor: working hard but not getting paid when the job was done. Authentication (Luo, 2002) in an e-commerce setting is necessary for $R \& D$ crowdsourcing. Consequently, both sourcers and sourcees must be authentically registered so that the CI will trust them both. In our case, cs.com recruited the candidates through an online job posting without a valid authentication system to verify sourcee qualifications, and failed to initiate swift trust between the sourcer and sourcee.

In China, crowdsourcers are commonly required to guarantee payment by depositing the full charge. When the task is completed successfully, the CI then releases the payment to the sourcee after collecting the $\mathrm{CI}$ commission. In our case, both QC and the manager of cs.com indicated concerns about the large deposit, but cs.com still asked QC to deposit the full amount. Because R\&D projects are usually quite costly, crowdsourcers take financial risk when make a full 
deposit. However, the crowdsourcees were assured payment by seeing that the CI held a full deposit. It is more difficult to build trust under high uncertainty and risk (Dong \& Glaister, 2007). Indeed, Cis must establish effective formal control mechanisms tailored to R\&D projects and minimizing e-commerce uncertainties through third-party recommendations, escrow services, and mutual ratings (Pavlou, 2002; Pavlou \& Gefen, 2004). In our case, cs.com failed to implement appropriate formal control mechanisms and to build swift trust. Hence, we propose several effective control mechanisms that CIs can adopt to drive swift trust:

Proposition 1. CI-based formal control mechanisms can build trilateral swift trust between crowdsourcers, CIs, and crowdsourcees.

Pla. Talent pools and mutual recommendation systems will help crowdsourcers trust CIs and crowdsourcees.

P1b. Authentication systems will help crowdsourcers and crowdsourcees build mutual trust.

P1c. Partial payment escrows and CI warranty systems will help crowdsourcers trust CIs, crowdsourcees trust CIs, and crowdsourcees trust crowdsourcers.

\section{Relational mechanisms and knowledge-based trust}

Also essential in the CI context is knowledge-based trust, based on knowledge and assessment of past behaviour (Robert et al., 2009). QC needed to trust that both cs.com and, particularly, that the selected crowdsourcee would be able to complete the R\&D task. CIs could use relational mechanisms requiring frequent interactions between partners to develop mutually reinforcing knowledge-based trust (Lavie, Haunschild, \& Khanna, 2012; Robert et al., 2009). 
Again, we observed that cs.com lacked proper relational mechanisms to establish knowledgebased trust among members. First, the project was not finished on time, which indicates poor performance management. Rachel explained:

It's not that we are not trusting QC; it's not that we intentionally delayed the job; it's purely our fault because of poor time management. We should have planned well. However, it would be helpful if the website could in some way monitor each project that is being crowdsourced on the platform.

The manager of cs.com also said:

We didn't do a good job monitoring the process. For sure, we have to reconsider the crowdsourcing mechanisms and website features.

This quote suggests that CIs must do more than just act as intermediaries to connect sourcers with sourcees. To keep the platform in business, they must also be facilitators using relational mechanisms to enhance knowledge-based trust between sourcers and sourcees. Performance management often requires formal control mechanisms. In the crowdsourcing context, a performance tracking application, such as a status report, could be the relational mechanism that enhances knowledge-based mutual trust. A status report allows the sourcee to provide regular progress reports that keep the sourcer informed so that both can track the progress and ensure that it is completed on time. In our case, QC never actually engaged in performance management. Therefore, it is no a surprise that Rachel failed to complete the task.

Cs.com also failed to provide a platform to allow QC to communicate directly with the sourcee. We suggest a workroom platform as a CI-based communication application that can 
allow sourcees and sourcers to directly interact. Both status reports and workrooms can facilitate open communication and timely information exchange to build the necessary mutual knowledge-based trust (Goo et al., 2009). The manager of cs.com later realized that the design of a performance tracking and communication applications is essential for R\&D CI settings.

Third, arbitration is necessary when sourcers and sourcees cannot resolve contract disputes. Arbitration strives for harmonious conflict resolution (Goo et al., 2009) and should be highlighted in the R\&D CI setting. In the case of cs.com, arbitration was more guanxi-based than legal-based, which might apply well in the Chinese context. However, a mature CI would require arbitration justice as an effective way of managing outsourcing risks if contractor performance is unsatisfactory (Vining, 1999). An arbitration mechanism will increase mutual trust between sourcers and sourcees, and their mutual trust in the CI.

Proposition 2. Relational governance mechanisms can help sourcers, sourcees, and CIs build trilateral knowledge-based trust.

P2a. Performance tracking systems will help sourcers and sourcees share knowledge-based trust.

P2b. CI-based communication systems will help sourcers and sourcees share knowledge-based trust. P2c. CI-based arbitration systems will help crowdsourcers/crowdsourcees trust the CI and will help crowdsourcers and crowdsourcees build mutual trust. 


\section{Guanxi and affect-based trust}

Affect-based trust is the overall trust environment that affects perceptions and behaviour. In China, guanxi indicates pre-existing informal relational connections that maintain affect-based trust. The manager of cs.com summarized the importance of guanxi:

People do business in China by guanxi in most cases, so the job is not outsourced to the most appropriate person, but to the most familiar person. So the key to success is to get to know the person.

Despite unenthusiastic attitudes towards the crowdsourcing model, both sourcers and sourcees are participating in the new practice, in accordance with trust transference theory (Stewart, 2003), even in an online environment. In this case, because both the sourcer and the sourcee trust the manager of cs.com, trust transferred through the guanxi network and they agreed to try the new model. In addition, they expressed positive support, as the manager from QC stated:

Companies have difficulties all the time, big or small. Sometimes they cannot solve them because of limited resources, like us. Our city is small, and we are short of talents; for China, the most excellent talents flow into big cities like Beijing and Shanghai. Therefore, if a mature crowdsourcing intermediary with solid mechanisms can protect its users from inappropriate behaviors or harm in the meantime, and if they can help us save costs, shrink working periods, and find better solutions for difficulties, why not try it? Initially, the manager of cs.com wanted to apply the fundamental idea of crowdsourcing: the open call for participants and the selection of candidates based on qualifications rather than 
personal guanxi. However, when the project began to show signs of failure, he used his personal guanxi to look for a substitute to finish the job. Otherwise, the project could have been a complete failure. As the manager of cs.com said:

The Internet has been changing the structure of Chinese society, including people-topeople trust. But it's a slow process. What we can do is to take full advantage of the surging trend of crowdsourcing and figure out the mechanisms to make it work, just like when e-commerce sprang up decades ago.

His statement shows that guanxi connections are still significant in the R\&D crowdsourcing market, and that relationship-based management capabilities and strategies potentially enhance product innovation (Xin \& Pearce, 1996). In fact, QC hired cs.com to crowdsource the project mainly because their managers knew one another personally. Cs.com selected Rachel as the service provider, but when they realized that she could not accomplish the task as expected, the cs.com manager used his personal relationships to find someone outside the sourcing pool to complete the task. In other words, he used guanxi connections as a contingent relational mechanism to ensure that the crowdsourcing project succeeded, to maintain the relationship, and, particularly, to restore affect-based trust with QC.

Intermediaries go beyond simply linking parties; they search for and transform ideas, and combine solutions to fit their clients (Hargadon \& Sutto, 1997). In the Chinese context, guanxi connections can be contingencies or supplements for finding the right crowdsourcers or crowdsourcees and enforcing transactions (Hennart, 2015). Indeed, in China, guanxi is more influential in the search for suitable suppliers than other information sources such as company 
websites, trade fairs, and the trade press (Millington et al., 2005). Guanxi-based transactions help maintain affect-based trust, but they can lower levels of swift and knowledge-based trust. In our case, cs.com retained their guanxi within the company, and provided no online path allowing Rachel and QC to directly communicate. Instead, cs.com monitored the progress and performance. When the project was failing, cs.com utilized their guanxi, which prevented the sourcers and sourcees from building swift and knowledge-based trust building or a continual working relationship. Nevertheless, open innovation should allow direct choice and engagement between sourcers and sourcees. Consequently, guanxi-based transactions violate the nature of open innovation and are a major hurdle for the organic growth of open innovation.

Our analysis leads to the following propositions:

Proposition 3a. In China, guanxi is a complementary and contingent relational governance mechanism for providing open innovation and maintaining affect-based trust.

Propostion 3b. In China, guanxi inhibits the development of swift-and knowledge-based trust and the organic growth of crowdsourcing-based open innovation.

\section{Discussion and Conclusions}

\section{Theoretical implications}

In our case study, we incorporate the literature of inter-organizational governance and trust development as a theoretical contribution to the open innovation literature. Although crowdsourcing can be used to drive open innovation (Zhao \& Zhu, 2012), few researchers have explored how innovation projects are successfully managed in the Internet environment. Our study underscores that Internet crowdsourcing intermediaries (CIs) are critical for providing 
open innovation opportunities to manage R\&D projects, but they must utilize appropriate governance mechanisms to facilitate trust development among crowdsourcers, crowdsourcees, and CIs. The case highlights the additional importance of relational governance mechanisms for managing highly complex R\&D crowdsourcing, such as through open and timely communication between sourcers and sourcees, mediation from the platform for resolving conflicts, and performance management tools. Considering that most open innovation studies have focused on western practices, we contribute by identifying effective governance mechanisms specific to the Chinese context (Byrum \& Bingham, 2016) and show that Chinese CIs should safeguard transactions and ensure that innovation projects will grow through customized technical functions such as partial payment and CI warranty systems.

Second, we extend the inter-organizational governance literature and e-commerce trust concept (Ba \& Pavlou, 2002; Benbasat, Gefen, \& Pavlou, 2008) to the R\&D crowdsourcing context, and thus contribute to understandings of trilateral trust building with intermediaries in business transactions (Svensson, 2004). Businesses traditionally use relational governance to enhance trust between intermediaries and buyers or between intermediaries and suppliers. They have no need to govern or enhance trust between suppliers and buyers. However, crowdsourcing involves a different business environment: crowdsourcing intermediaries are facilitators and must provide formal and relational governance mechanisms to enhance swift-trust and knowledge-based trust between crownsourcers and crowdsourcees. Swift trust encourages their initial contact; knowledge-based trust further ensures that they will return for future transactions. 
The proposed trilateral trust building is therefore critical to provide a healthy environment for the growth of crowdsourcing-based open innovation.

Third, we offer additional understanding of China's guanxi tradition and provide evidence that it can have double-edged functions (Chen et al., 2013) for the growth of crowdsourcing. Guanxi provides social capital that substitutes for formal institutional support (Xin \& Pearce, 1996), enforces transactions (Carlile, 2002; Hennart, 2015), and provides business opportunities (Wong, 2007). Therefore, guanxi connections are contingent formal control and relational governance mechanisms for maintaining affect-based trust. However, they can inhibit swift- and knowledge-based trust development among key players in China's R\&D crowdsourcing marketplace. In our case study, guanxi prevented the CI from providing open and transparent selection of crowdsourcers and crowdsourcees, which indicates that ventures pursuing new technological innovations may find guanxi to be an ineffective strategy (Li \& Atuahene-Gima, 2001). We suggest that the cultural tradition of guanxi as a prerequisite for business relationships violates the needs of $\mathrm{R} \& \mathrm{D}$ crowdsourcing to provide open biddings and open communications, and is, consequently, a major barrier to the growth of open innovation in China.

\section{Limitations and future studies}

Our study has limitations that should be considered. We urge practitioners and researchers in the field to further examine crowdsourcing in other areas. First, we examined the issue from the perspective of trust building, but Chinese businesses may avoid crowdsourcing R\&D tasks for other reasons, such as the characteristics of the tasks and management issues. We challenge 
future research to follow up the study and offer more insights, particularly by exploring nonintermediary and re-intermediary processes (Sun, 2006) and comparing the new online crowdsourcing model with traditional intermediary services. Second, our single case study helps to explain the research context, but case studies lack transferability. Future studies could incorporate additional cases to allow "replication" logic to confirm or disconfirm conceptual insights (Brown \& Eisenhardt, 1997; Yin, 2009). Third, we conclude with managerial implications to be drawn from the analysis. Future study could use a quantitative approach to test the concept empirically and continue to enhance understandings.

\section{Managerial implications}

China will gradually and inevitably accept open innovation and thus provides a dynamic setting for examining firms as they adopt crowdsourcing as the open innovation approach.. Therefore, our study provides practical implications for the development of crowdsourcing in China. That is, we show that trust is essential for all three entities involved in $R \& D$ crowdsourcing. To meet the demand for innovation through Internet-based crowdsourcing in China, CIs should build trust by incorporating and promoting various website features to build personal and social relationship among crowdsourcers and crowdsourcees.

Clearly, guanxi practice continues to affect innovation crowdsourcing in China, although guanxi is declining as modern China transitions toward legal contracts (Guthrie, 1998). Organizations with substantial resources, minor agency problems, and well-structured or formalized routines are likely to use contracts as their basic governance mechanism. In contrast, organizations with few resources, acute agency problems, and informal, relation-oriented 
organizational routines are more likely to use guanxi as a governance mechanism (Zhang \& Keh, 2010). To minimize the reliance on guanxi and to develop the marketplace for open innovation, Chinese CIs must gradually build their talent pools for crowdsourcing R\&D projects and strengthen their formal control, relational mechanisms, and performance management tools; for example through escrow systems and arbitration processes.

\section{Conclusion}

Our case study allowed us to observe the developing trend of Internet-based crowdsourcing to achieve open innovation in China and to identify the challenges facing $R \& D$ crowdsourcing. We identify inter-organizational governance mechanisms for building trilateral trust among crowdsourcers, crowdsourcing intermediaries, and crowdsourcees. We propose that formal control and relational governance mechanisms must be adapted to the Chinese context. We highlight that guanxi is a temporary relational source but a long-term barrier to the growth of open innovation in China. 


\section{REFERENCES}

Andriole, S. J. (2010). Business impact of Web 2.0 technologies. Communications of the ACM, 53(12), 67-79.

Ba, S., \& Pavlou, P. A. (2002). Evidence of the effect of trust building technology in electronic markets: Price Premiums and Buyer Behavior. MIS Quarterly, 26(3), 243-268.

Bachmann, R., \& Inkpen, A. C. (2011). Understanding institutional-based trust building processes in inter-organizational relationships. Organization Studies, 32(2), 281-301.

Benbasat, I., Gefen, D., \& Pavlou, P. A. (2008). Special issue: Trust in online environments. Journal of Management Information Systems, 24(4), 5-11. doi: Doi 10.2753/Mis0742-1222240400

Bjørnskov, C. (2007). Determinants of generalized trust: A cross-country comparison. Public Choice, 130(1-2), 1-21.

Bourgeois, L. J., \& Eisenhardt, K. M. (1988). Strategic decision processes in high velocity

environments: Four cases in the microcomputer industry. Management Science, 34(7), 816-835.

Brabham, D. C. (2008). Crowdsourcing as a model for problem solving: an introduction and Cases. Convergence: the international journal of research into new media technologies, 14(1), 7590.

Brown, S. L., \& Eisenhardt, K. M. (1997). The art of continuous change: Linking complexity theory and Time-paced evolution in relentlessly shifting organizations. Administrative Science Quarterly, 41(1), 1-34.

Byrum, J., \& Bingham, A. (2016). Improving analytics capabilities through crowdsourcicng. MIT Sloan Management Journal, 57(4), 43-48.

Cabiddu, F., Castriotta, M., Di Guardo, M. C., \& Floreddu, P. (2013). Open Innovation and Crowdsourcing Communities Design: A Cross Case Analysis Designing

Organizational Systems pp. 143-155: Springer.

Carlile, P. R. (2002). A pragmatic view of knowledge and boundaries: Boundary objects in new product development. Organization Science, 13(4), 442-455.

Chen, C. C., Chen, X. P., \& Huang, S. (2013). Chinese Guanxi: An integrative review and new directions for future research. Management and Organization Review, 9(1), 167-207.

Chesbrough, H. (2006). Open Innovation: a New Paradigm for Understanding Industrial Innovation. In Henry Chesbrough, Wim Vanhaverbeke \& J. West (Eds.), Open innovation: Researching a new paradigm pp. 1-12: Oxford University Press.

Chesbrough, H. W. (2003). Open innovation: The new imperative for creating and profiting from technology: Harvard Business Press.

Chua, R. Y., Morris, M. W., \& Ingram, P. (2009). Guanxi vs networking: Distinctive configurations of affect-and cognition-based trust in the networks of Chinese vs American managers. Journal of International Business Studies, 40(3), 490-508. 
Das, T. K., \& Teng, B. S. (1998). Between trust and control: Developing confidence in partner cooperation alliances. Academy of Management Review, 23(3), 491-512.

Davison, R. M., \& Ou, X. C. (2008). Guanxi, knowledge and online intermediaries in China. Chinese Management Studies, 2(4), 281-302.

Doney, P. M., \& Cannon, J. P. (1997). An Examination of the nature of trust in buyer-seller relationships. Journal of Marketing, 61(2), 35-51.

Dong, L., \& Glaister, K. W. (2007). The management of culture in Chinese international strategic alliances. Asian Business \& Management, 6(4), 377-407.

Dyer, J. H., \& Singh, H. (1998). The relational view: Cooperative strategy and sources of interorganizational competitive advantage. Academy of Management Review, 23(4), 660-679.

Economist Intelligence Unit. (2008). The Role of Trust in Business Collaboration: An Economist Intelligence Unit briefing paper sponsored by Cisco Systems.

Erickson, L. (2012). Hanging with the right crowd: Matching crowdsourcing need to crowd characteristics. Paper presented at the the Proceedings of Americas Conference on Information Systems, Seattle, USA.

Feeser, H. R., \& Willard, G. E. (1989). Founding strategy and performance: A comparison of high and low growth high tech firms. Journal of Business Venturing, 4(6), 429-442.

Frey, K., Lüthje, C., \& Haag, S. (2011). Whom should firms attract to open innovation platforms? The role of knowledge diversity and motivation. Long Range Planning, 44(5), 397-420.

Gambetta, D. (1988). Trust: Making and Breaking Cooperative Relations. Cambridge Blackwell Ltd.

Gassmann, O., \& Han, Z. (2004). Motivations and barriers of foreign R\&D activities in China. $R \& D$ Management, 34(4), 423-437.

Gefen, D., \& Straub, D. W. (2004). Consumer trust in B2C e-Commerce and the importance of social presence: experiments in e-Products and e-Services. Omega-International

Journal of Management Science, 32(6), 407-424. doi: DOI 10.1016/j.omega.2004.01.006

Golden, B. R. (1997). Further remarks on retrospective accounts in organizational and strategic management research. Academy of Management Journal, 40(5), 1243-1252.

Goo, J., Kishore, R., Rao, H. R., \& Nam, K. (2009). The role of service level agreements in relational mnagement of information technology outsourcing: An empirical study. MIS Quarterly, 33(1), 119-145.

Guthrie, D. (1998). The declining significance of guanxi in China's economic transition. The China Quarterly, 154, 254-282.

Hödl, M. K., \& Puck, J. F. (2014). Asset specificity, IJV performance and the moderating effect of trust: Evidence from China. Asian Business \& Management, 13(1), 65-88.

Hamilton, D. L., \& Sherman, S. J. (1996). Perceiving Persons and Groups. Psychological Review, 103(2), 336.

Hargadon, A., \& Sutton, R. I. (1997). Technology brokering and innovation in a product development firm. Administrative Science Quarterly, 42(42), 716-749. 
Heiskanen, A. (1995). Reflecting over a practice: Framing issues for scholar understanding. Information Technology \& People, 8(4), 3-18.

Heiskanen, A., \& Newman, M. (1997). Bridging the gap between information systems research and practice: the reflective practitioner as a researcher. Paper presented at the Eighteenth International Conference on Information Systems, December 15-17, 1997, Atlanta, Georgia, USA.

Heiskanen, A., Newman, M., \& Eklin, M. (2008). Control, trust, power, and the dynamics of information system outsourcing relationships: A process study of contractual software development. Journal of Strategic Information Systems, 17(4), 268-286.

Hennart, J.-F. (2015). Leveraging Asian institutions to deepen theory: A transaction cost perspective on relational governance. Asian Business \& Management, 14(2), 257-282.

Howells, J. (2006). Intermediation and the role of intermediaries in innovation. Research Policy, 35(5), 715-728.

Huber, G. P., \& Power, D. J. (1985). Retrospective reports of strategic-level managers: Guidelines for increasing their accuracy. Strategic Management Journal, 6(2), 171180.

Huff, L., \& Kelley, L. (2003). Levels of organizational trust in individualist versus collectivist societies: A seven-nation study. Organization Science, 14(1), 81-90.

Hutchings, K., \& Murray, G. (2002). Australian expatriates' experiences in working behind the Bamboo curtain: an examination of Guanxi in post-communist China. Asian Business \& Management, 1(3), 373-393.

Katsikeas, C. S., Skarmeas, D., \& Bello, D. C. (2009). Developing successful trust-based international exchange relationships. Journal of International Business Studies, 40(1), 132-155.

Katzy, B., Turgut, E., Sailer, T. H., \& Klaus. (2013). Innovation intermediaries: a process view on open innovation coordination. Technology Analysis \& Strategic Management, 25(3), 295-309.

Kee, H. W., \& Knox, R. E. (1970). Conceptual and methodological considerations in the study of trust and suspicion. Journal of Conflict Resolution, 14(3), 357-366.

Kramer, R. M. (1999). Trust and distrust in organizations: Emerging perspectives, enduring questions. Annual Review of Psychology, 50(1), 569-598.

Lacity, M. C., Khan, S. A., \& Willcocks, L. P. (2009). A review of the IT outsourcing Literature: Insights for practice. Journal of Strategic Information Systems, 18(3), 130-146.

Lavie, D., Haunschild, P. R., \& Khanna, P. (2012). Organizational differences, relational mechanisms, and alliance performance. Strategic Management Journal, 33(13), 1453-1479.

Lee, Y., \& Cavusgil, S. T. (2006). Enhancing alliance performance: The effects of contractual-based Versus relational-based governance. Journal of Business Research, 59, 896-905.

Li, H., \& Atuahene-Gima, K. (2001). Product innovation strategy and the performance of new technology ventures in China. Academy of Management Journal, 44(6), 1123-1134. 
Luo, X. (2002). Trust production and privacy concerns on the Internet: A framework based on relationship marketing and social exchange theory. Industrial Marketing Management, 31(2), 111-118.

Macneil, I. R. (1980). The New Social Contract: An Inquiry into Modern Contractual Relations: Yale University Press.

Majchrzak, A., \& Malhotra, A. (2013). Towards an information systems perspective and research agenda on crowdsourcing for innovation. Journal of Strategic Information Systems, 22(4), 257-268.

Martinsons, M. G. (2008). Relationship - based e - commerce: theory and evidence from China. Information Systems Journal, 18(4), 331-356.

McEvily, B., Perrone, V., \& Zaheer, A. (2003). Trust as an organizing principle. Organization Science, 14(1), 91-103.

Miles, M. B., \& Huberman, A. M. (1994). Qualitative Data Analysis: An Expanded Sourcebook: Sage.

Miller, C. C., \& Glick, W. H. (1997). Retrospective reports in organizational research: A ReExamination of Recent Evidence. Academy of Management Journal, 40(1), 189-204.

Millington, A., Eberhardt, M., \& Wilkinson, B. (2005). Gift giving, guanxi and illicit payments in buyer-supplier relations in China: Analysing the experience of UK companies. Journal of Business Ethics, 57(3), 255-268.

Myers, M. D. (2013). Qualitative Research in Business and Management: Sage.

Park, S. H., \& Luo, Y. (2001). Guanxi and organizational dynamics: Organizational networking in Chinese firms. Strategic Management Journal, 22(5), 455-477.

Pavlou, P. A. (2002). Institution-based trust in interorganizational exchange relationships: the role of online B2B marketplaces on trust formation. Journal of Strategic Information Systems, 11, 215-243.

Pavlou, P. A., \& Gefen, D. (2004). Building effective online marketplaces with institution-based trust. Information Systems Research, 15(1), 37-59.

Pedersen, J., Kocsis, D., Tripathi, A., Tarrell, A., Weerakoon, A., Tahmasbi, N., De Vreede, G.-J. (2013). Conceptual foundations of crowdsourcing: A review of IS research.

Paper presented at the the 46th Hawaii International Conference on System Sciences (HICSS).

Robert, L. P., Denis, A. R., \& Hung, Y.-T. C. (2009). Individual swift trust and knowledge-based trust in face-to-face and virtual team members. Journal of Management Information Systems, 26(2), 241-279.

Sabherwal, R. (1999). The role of trust in outsourced IS development projects. Communications of the ACM, 42(2), 80-86.

Saldaña, J. (2012). The Coding Manual for Qualitative Researchers: Sage.

Schön, D. (1983). The Reflective Practitioner: How Professionals Think in Action. New York: Basic Books. 
Shapiro, S. P. (1987). The social control of impersonal trust. American Journal of Sociology, 93(3), 623-658.

Sieg, J. H., Wallin, M. W., \& Von Krogh, G. (2010). Managerial challenges in open innovation: a study of innovation intermediation in the chemical industry. $R \& D$ Management, 40(3), 281291.

Stewart, K. J. (2003). Trust transfer on the world wide web. Organization Science, 14(1), 5-17.

Sun, K-q. (2006). 'Non-intermediary and Re-intermediary in E-commerce', Journal of Yunnan University of Finance and Economics, 1, 008.

Svensson, G. (2004). Triadic trust in business networks: A conceptual model and empirical illustration. European Business Review, 14(2), 165-190.

Terwiesch, C., \& Xu, Y. (2008). Innovation contests, open innovation, and multiagent problem solving. Management Science, 54(9), 1529-1543.

Tran, Y., Hsuan, J., \& Mahnke, V. (2011). How do innovation intermediaries add value? Insight from new product development in fashion markets. $R \& D$ Management, 4l(1), $80-91$.

Ulset, S. (1996). R\&D outsourcing and contractual governance: An empirical study of commercial R\&D projects. Journal of Economic Behavior \& Organization, 30(1), 63-82.

Verner, J. M., \& Abdullah, L. M. (2012). Exploratory case study research: Outsourced project failure. Information and Software Technology, 54(8), 866-886.

Verona, G., Prandelli, E., \& Sawhney, M. (2006). Innovation and virtual environments: towards virtual knowledge brokers. Organization studies, 27(6), 765-788.

Vining, A. (1999). A conceptual framework for understanding the outsourcing decision. European Management Journal, 17(6), 645-654.

West, J., \& Bogers, M. (2014). Leveraging external sources of innovation: a review of research on open innovation. Journal of Product Innovation Management, 31(4), 814-831.

Willamson, O. (1985). The Economic Institutions of Capitalism. New York.

Wong, M. (2007). Guanxi and its role in business. Chinese Management Studies, 1(4), 257-276.

Xin, K. K., \& Pearce, J. L. (1996). Guanxi: Connections as substitutes for formal institutional support. Academy of Management Journal, 39(6), 1641-1658.

Yin, R. K. (2003). Applications of Case Study Research Thousand Oaks: Sage Publications.

Yin, R. K. (2009). Case Study Research - Design and Methods: Sage Publications, Inc.

Zaheer, A., McEvily, B., \& Perrone, V. (1998). Does trust matter? Exploring the effects of interorganizational and interpersonal trust on performance. Organization Science, 9(2), 141-159.

Zaheer, A., \& Venkatraman, N. (1995). Relational governance as an interorganizational strategy: An empirical test of the role of trust in economic exchange. Strategic Management Journal, 16(5), 373-392.

Zhang, J., \& Keh, H. T. (2010). Interorganizational exchanges in China: Organizational forms and governance mechanisms. Management and Organization Review, 6(1), 123-147. 
Zhao, Y., \& Zhu, Q. (2012). Evaluation on crowdsourcing research: Current status and future direction. Information Systems Frontier, 16(3), 417-434.

Zogaj, S., Bretschneider, U., \& Leimeister, J. M. (2014). Managing crowdsourced software testing: A case study based insight on the challenges of a crowdsourcing intermediary. Journal of Business Economics, 1-31.

Zucker, L. G. (1986). Production of trust: Institutional sources of economic structure, 1840- 1920, Research in Organizational Behavior, 8(2),53-111. 
Figure 1. Trilateral Trust Relationships in the CI Setting

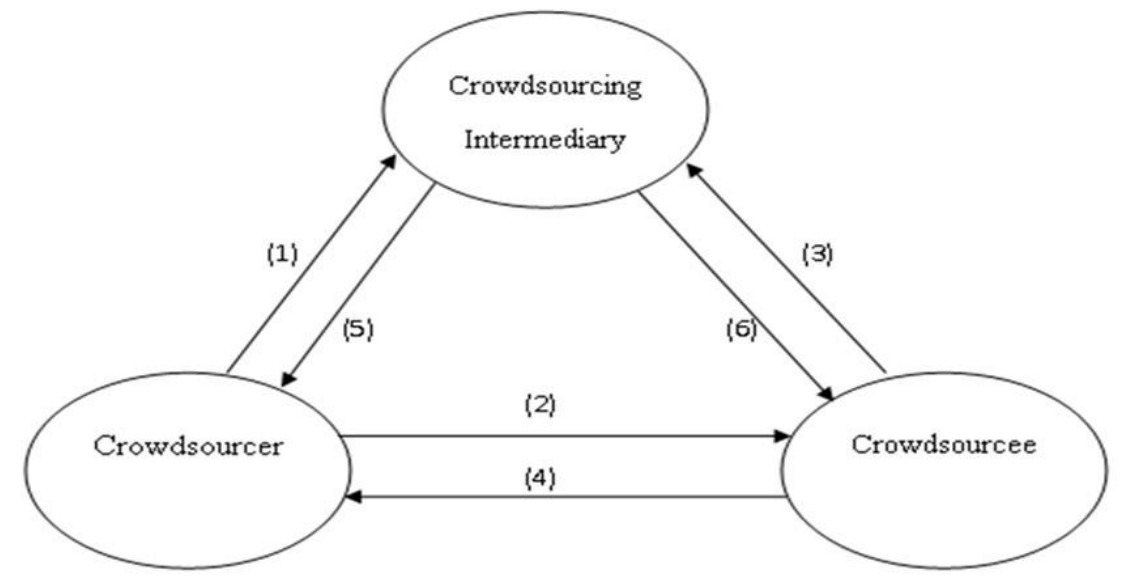

Figure 2. The Summary of Findings

\section{Chinese Context Barriers}

\section{Result of Trust}

\section{Weak Formal Control}

- Inappropriate talent pool

Undeveloped practices

- Weak talent evaluation

- Lack of authentication

Weak Swift Trust

- Full deposit requirement

\section{Weak Relational Governance}

\begin{tabular}{|c|c|c|}
\hline \multirow{2}{*}{$\begin{array}{l}\text { Guanxi } \\
\text { relationship }\end{array}$} & - Highly involv & Based Trust \\
\hline & $\begin{array}{l}\text { - No communication between } \\
\text { sourcers and sourcees } \\
\text { - Lack of arbitration system }\end{array}$ & $\begin{array}{l}\text { Strong Affect-Based } \\
\text { Trust }\end{array}$ \\
\hline
\end{tabular}




\section{Appendix}

Cs.com initially invited six companies to use crowdsourcing.

Employees were asked to respond to the following questionnaire, according to their work experience:

1. Do you think your organization will crowdsource their R\&D tasks to external clients, for example, through an Internet-based platform? If yes, list the reasons. If not, what resistances or concerns do you expect?

2. How will the Chinese macro-environment positively and negatively influence trust regarding $\mathrm{R} \& \mathrm{D}$ crowdsourcing activities in China?

3. What mechanisms will be effective for regulating vendor behaviours in Internet R\&D crowdsourcing?

4. What specific changes in the macro-environment are needed to improve the development of $\mathrm{R} \& \mathrm{D}$ crowdsourcing?

General manager of cs.com:

1. What are the advantages and disadvantages of $R \& D$ crowdsourcing in China? What benefits or resistance will China's macro-environment bring to R\&D crowdsourcing activities in China?

2. What difficulties did you encounter when you looked for vendors to bid for the tasks on cs.com? Please list common concerns that vendors might have.

3. When you looked for clients to place tasks on cs.com, what difficulties did you encounter? Please list common concerns that clients might have.

4. How is R\&D crowdsourcing unique to China in comparison with the popular crowdsourcing intermediaries in the United States or Europe?

5. How does the macro-environment of Chinese society positively and negatively affect trust in R\&D crowdsourcing processes?

6. What arbitration role should cs.com play? Is it necessary?

7. What will cs.com do to improve client/vendor trust? Will cs.com take concrete measures?

8. How should China's macro-environment be changed specifically to improve the development of R\&D crowdsourcing?

Artifact Designer/Director:

1. When the development team designed the website, did they consider trust as a factor? What has the company done to improve trust?

2. How was the website developed to increase user trust? How effective was it?

3. Have users made any suggestions to cs.com since it launched? 
4. How should China's macro-environment be changed to improve the development of R\&D crowdsourcing?

\section{Manager of QC Corporation}

1. Compared with traditional outsourcing approaches, are you willing to use an online crowdsource approach to handle your R\&D tasks? What do you think about Internetbased R\&D crowdsourcing?

2. Do you trust cs.com and the client? Do you think they will do a good job?

3. Were you satisfied with the online crowdsourcee? Did cs.com recommend a sourcee?

4. Did you encounter difficulties in completing the transaction? How did you solve the problem?

5. How do you feel about your contract with cs.com? Did it cover all your concerns? Did it fail to cover any issues? How can problems be solved if they arise?

Rachel:

1. Why were you motivated to take an online job?

2. Did you trust cs.com and the tasks it advertised?

3. Why did you fail to finish the transaction with the QC Corporation?

4. What do you think about cs.com's design and website features? Are you satisfied with the payment and work mode?

5. What aspects of cs.com should be improved to attract more users?

Jack:

1. Why are you motivated to take online jobs?

2. Do you trust cs.com and the tasks it advertises?

3. What do you think about cs.com's design and website features? Are you satisfied with the payment and work mode?

4. What aspects of cs.com should be improved to attract more users?

Note: Jack and Rachel were crowdsourcees at two phases, so their questionnaires differ. 